\title{
The Effects of Ageing Population on Health Expenditure and Economic Growth in China: A Bayesian-VAR Approach
}

\begin{abstract}
The increasing proportion of the population aged 65 or over has generated a global rise of health spending due to higher demand for medical and long-term care services, which has become a growing challenge to the sustainability of public finances across countries. This phenomenon is especially prominent in China, which has experienced accelerated rates of both economic growth and population ageing over the past four decades. Using Bayesian-VAR (B-VAR) models we compute the impulse response functions (IRFs) and the forecast error variance decomposition functions (FEVDs) to empirically examine the dynamic relationships between ageing index, life expectancy, economic growth and health expenditure in China. We compare China with the USA which has distinct trajectories of population structure and economic development to better understand the former's dynamic patterns. We find a pronounced response for both the USA and China of ageing index to life expectancy and of health spending per capita to GDP per capita, while ageing population induces a relatively strong reaction from health expenditure per capita in China. Our results are robust with either nominal or real variables. These findings suggest that, in China, a well-rounded policy accommodating economic, social and health factors is needed to improve the quality of life of the ageing population for a sustainable development of the economy.
\end{abstract}

Keywords: Bayesian-VAR models; ageing population structure; health spending; policy implications; China.

JEL Classification: I1, I15, J11 


\section{Introduction}

Health expenditure plays an important role in people's wellness and in countries' economic development (Fogel 2002; 2004). In both developed and developing countries, health expenditure is highly and positively correlated with economic growth (Wang 2011; Braedle et al. 2016; Murthy et al. 2016; Lopreite and Mauro 2017). In particular, economic growth leads to increases in demand for medical services. Subsequent increases in life expectancy in turn lead to greater health expenditure (Werblow et al. 2007; Harper 2014). Moreover, large elderly cohorts have led to increased incidence rates of chronic diseases (i.e. cardiovascular diseases, cancer, chronic renal disease, diabetes and their respective complications) and higher demand of long-term healthcare services including expensive technologies and hospitalisation which has put the sustainability of healthcare systems at risk (Fujino 1987; Murthy and Ukpolo 1994; Feng et al. 2020). On the other hand, greater health expenditure leads to increased availability of medical products and long-term healthcare services with a parallel rise of longevity (Kunze 2014). The resulted labour force with improved health status positively affects labour quality and labour productivity and therefore drives economic development and growth (Linden et al. 2017; Alvarez-Galvez et al. 2018).

In recent decades, major developing economies such as China have experienced a substantial demographic transition due to both declines in fertility and increases in life expectancy. Compared with developed countries such as the USA that has had decades to adjust gradually its health spending to its ageing population, China's ageing process started at an earlier stage of development and it was faster.

In China from 1978-2017 the share of population aged 65 or over increased from 4.45 percent to 10.64 percent with a significant impact on health spending and economic growth (Fougere et al. 1999; Bloom et al. 2015; Choi et al. 2015; Uddin et al. 2016). In the same period other indicators such as fertility rate declined from 2.9 percent to 1.6 percent and life expectancy increased from 65 to 76 , 
both in consequence of China's one-child policy further amplifying the negative effect of population ageing on health expenditure.

In fact, the rapid fertility reduction associated with the one-child policy in China may have a negative impact on the elderly, as they might no longer be able to receive support from their children. Furthermore, the demographic shift may move China from a global source of low-cost workers to an economy suffering healthy labour shortages as the country approaches its Lewis Turning point from 2020-2030 (IMF 2013). It is expected that China will become the world's most aged society in 2050 with the percentage of Chinese population above the retirement age projected to be almost tripled from 9.6 in 2015 to 27.6 in 2050 . At the same time the elderly dependency ratio is expected to increase from 0.13 to 0.47 (UNPD 2015a). The old pension programmes in China penalise working in old age and encourage early retirement whereas population ageing makes it necessary to prolong the working lives to compensate for the increasing public eldercare costs. China will have proportionally smaller working-age population and a surge of retirees that will soon prompt questions on its ability of providing eldercare. The challenges of maintaining the sustainability of public finances and of managing the shortage of labour supply are thus driving the Chinese government to reform its retirement systems (UNPD 2015b). These effects will impose several constraints on China's economic development and China could quickly lose its competitive edge to other emerging economies such as India and Indonesia, which increases its risk of falling into the "middle incometrap" (Cai, 2012).

According to China's National Bureau of Statistics (2015) there were on average 27 beds in elderly care institutions per 1000 senior citizens in China in 2015, while there were respectively 37 beds in the USA and 55 in Germany (OECD 2017). In addition, the recent slowdown in China's economic growth may reduce its health spending, with negative consequences on the quality of healthcare as well as on life expectancy.

These observations suggest that China needs to readjust its policies in order to provide additional resources to the elderly and their households and to break the intergenerational cycle of poverty. To 
achieve these goals, it is crucial for the policymakers to understand the relationships between health spending, ageing, life expectancy and economic growth in China.

The aim of this paper is to test these relationships empirically using the Bayesian vector autoregression (Bayesian-VAR or B-VAR) econometric techniques. The results will help policymakers better understand the dynamic interactions between the rapid growth of the older segment of the population in China and its healthcare and economic systems which are still far from adequately supporting the elder boom.

The remainder of the paper is organised as follows. In Section 2 we present a summary of literature review and highlight our contributions. We pay particular attention to the studies exploring the empirical causal relationships between health spending per capita, GDP per capita, life expectancy and population ageing. In Section 3 we introduce the Bayesian VAR methodology and explain why it fits well with the aims of our study. In Section 4 we describe the data used in our empirical analysis. In Section 5 we show the results of the impulse response functions (IRFs) and the forecast error variance decomposition functions (FEVDs) and compare China with the USA for the same period of time. In Section 6 we evaluate the forecast accuracy of the frequentist VAR model and that of the BVAR model with different prior specifications (e.g. Minnesota prior versus Normal-inverse-Wishart prior). Finally, in Section 7 we test the robustness of the results by repeating the analysis for the same period of time with real GDP per capita and real health expenditure per capita before we conclude the paper.

\section{Literature Review}

We have performed a critical review of the literature that explores empirical relationships between the four variables, health expenditure, population ageing, life expectancy and economic growth.

We use generally acknowledged databases such as Scopus, Google Scholar and PubMed. The search terms (i.e. key variables) employed in identifying the relevant literature include: "ageing (OR 
longevity) AND health expenditure (OR health spending OR cost) AND economic growth (OR GDP) AND life expectancy".

The above four variables are interrelated with each other. The relationship between life expectancy and population ageing is a straightforward one as the latter is driven by increases in the former combined with declines in fertility rates. The empirical studies collected from our search strategy typically focus on one relationship (between a pair of variables) at a time. Therefore three strands of literature are summarised below depending on which of the three pairwise relationships between the three variables, health expenditure, population ageing (or life expectancy) and economic growth, is investigated.

Firstly, we focus on the studies that assess the causal relationship between health spending and economic growth while grouping them in terms of one-way or two-way causality relations.

Several studies analysing the one-way relationship between health spending and economic growth have stressed the importance of economic growth in health expenditure. For instance, Gerdtham et al. (2010) reveal that GDP per capita contributes significantly to the explanation of the health care expenditure's variation between the 19 OECD countries. Braendle and Colombier (2016) show that income per capita is positively related to health care expenditure growth. Baltagi and Moscone (2010) using the data of 20 OECD countries over the period 1971-2004 demonstrate that health expenditure is a necessity rather than a luxury.

Other studies, instead, have found a two-way causal relationship between health expenditure and economic growth. For instance, Wang (2011) analyses the data of 31 countries from 1986 to 2007 to explore the causality between an increase in healthcare expenditure and economic growth. He finds that health care expenditure growth stimulates economic growth whereas economic growth reduces expenditure growth. The findings of Amiri and Ventelou (2012) indicate that there exists a bidirectional Granger causality between GDP and healthcare expenditure in OECD countries. Amiri and Linden (2016) using the sample of 22 OECD countries find during the period 1970-2012 that a bilateral relationship between GDP and aggregate healthcare spending is widely predominant in the 
vast majority of OECD countries. Halici-Tuluce et al. (2016) show that a reciprocal relationship exists between health spending and economic growth in the short run for both low and high-income economies in their sample. Finally, Chaabouni et al. (2016) and Chaabouni et al. (2017) find a bidirectional relationship between health spending and economic growth for the period 1995-2013 in 51 countries with low-middle or high income level.

Secondly, the relationship between population ageing (or life expectancy) and health expenditure has also been studied in the literature. For example, Breyer and Felder (2006) find that the expanding of medical technology has a much larger impact on healthcare expenditure than ageing in Germany. Kildemoes et al. (2006) show that the population ageing in Denmark is likely to increase future expenditure on prescription drugs. Jaba et al. (2014) collecting the data for 175 countries obtain for the years 1995-2010 a significant relationship between health expenditure and life expectancy using a panel model. Murthy and Okunade (2016) using the annual data from 1960-2012 and the ARDL (autoregressive distributed lag cointegration) approach identify real income per capita, the share of population aged 65 or over and the level of health care technology as the major drivers of health expenditure per capita. Linden and Ray (2017) find a positive relationship between public health expenditure (in particular private expenditure) and life expectancy for 34 OECD countries between the years 1970 and 2012. Lopreite and Mauro (2016) using Bayesian-VAR (B-VAR) models show that health spending in Italy for 1990-2013 reacts more to ageing index than life expectancy and economic growth. Gallet and Doucouliagos (2017) using a meta-regression analysis find evidence of a greater effect on health spending of mortality rate compared to life expectancy. Obrizan and Wehby (2018) suggest that increasing health spending in countries with low life expectancy may have important returns to life expectancy. All in all, the existing literature investigating the relationships between health expenditure and its major drivers give different results which depend on data type (macro or micro) and on model specification. Moreover, the impact of several demographic changes (i.e. as number of people over a certain age, number of people with a given disabilities or chronic disease) on the health spending is still not clear and varies substantially. 
Finally, the relationship between population ageing and economic growth is also a reciprocal one as population age structure affects the pace of economic growth and economic performance leads to demographic changes as well. It has been well documented that an enlarged share of population in the working ages (i.e., an increase in the support ratio) generates the "first demographic dividend" in emerging Asia (Bloom and Williamson 1998, Lee et al. 2000). Mason and Lee $(2006,2007)$ further explores the possibility of a "second demographic dividend" through the accumulation of human and physical capital as more recently low fertility rates and high life expectancy lead to population ageing and a decline in the support ratio. Bloom et al. (2010a) have considered the economic impacts of population ageing through the lens of accounting, behavioural and institutional effects and their counterfactual exercises (assuming 2005-2050 growth rate of labour force per capita for 1960-2005) suggest modest declines of economic growth rates for OECD countries and an insignificant impact on the pace of economic growth in developing countries.

Our contribution to the existing literature is at least twofold. Firstly, unlike the above-mentioned studies, we consider the relationships between health expenditure, ageing index, life expectancy and economic growth and investigate all the possible directions of causality. In order to do this, we use the Bayesian-VAR (B-VAR) methodology, which is especially suitable for short samples as in our case and offers better results than a classical VAR model. Moreover, we estimate a B-VAR model based on the Minnesota prior specification, which incorporates useful belief information on the distributions of parameters. As a result, we are able to conduct both short and medium-run analyses by computing the impulse response functions (IRFs) and the forecast error variance decomposition functions (FEVDs) and evaluate the forecasting performance.

Secondly, we conduct a comparative analysis between China and the USA which are characterised by significant differences in the dynamics of their economic development and population age structure. In fact, the USA has long been considered as an "ageing society" (Llotyd-Scherlock et al. 2000; Bloom et al. 2010a) whereas China is characterised by "getting old before getting rich" (Qiao, 2006). As shown in Figure A1 in the appendix, although China has achieved phenomenal economic 
growth over the past several decades, its income and health expenditure per capita is still far behind the levels in the USA. However, the rates of life expectancy and population ageing in China have clearly accelerated over the past two decades and will soon arrive at the same levels as in the USA. Therefore, a comparative analysis between China and the USA enables us to interpret the results in context.

\section{Methodology: Setting the Prior for the B-VAR Estimation}

Over the past several decades the VAR models have been largely used as standard tools in macroeconomic analysis and forecasting (Sims 1980, 1992; Christiano et al.1999). The popularity of VAR models is due not only to their simple formulation but to that they are very successful in capturing dynamic linear relationships between time series without imposing restrictions on parameters as in structural VAR models. However, they show several problems when the frequentist approach is applied to VAR estimation. Firstly, a typical VAR model works better with a small number of variables. Thus, we may have a risk of 'overfitting' in the case of a large number of parameters (risk present also with moderate size) as the number of unrestricted parameters that can be estimated is limited. Secondly, since the VAR models usually include a few variables they tend to be poor models in forecasting and in structural analysis for omitted variables bias (Christiano et al.1999; Giannone and Reichlin 2006). Finally, the VAR approach suffers from the loss of degree of freedom if the lag length increases and becomes too large. In this case we have large standard errors and then unstable point estimates.

These problems are particularly relevant in our context, where, due to the lack of data, we can perform our analysis only on a short period of time (1978-2016). One of the advantages of the B-VAR approach is to overcome the problems associated with overfitting and the poor forecasting performance introduced by the VAR methodology when the dataset is short, the sample information 
is weak or the number of the parameters is large (Litterman 1981, 1986; Sims 1982; Doan et al. 1984; Stock and Watson 2001; Canova 2007; Banbura et al. 2010; Auer 2014; Kanngiesser et al. 2019). The Bayesian inference using the parameter shrinkage, which we describe below, improves the dynamic analysis and forecasting accuracy of the models.

Specifically, it is possible to reduce the estimation error and to have only a small bias on the parameters for the restrictions (priors) on the coefficients assuming that they are more likely close to zero with respect to the coefficients of the shorter lags (Litterman 1981, 1986; Doan et al. 1984).

The use of the B-VAR, with the help of the priors as the key factor, makes additional knowledge available during the estimation and hence achieves better results without the need of requiring restricted models (i.e. models with many coefficients set to zero). Specifically, the Bayesian approach combines the sample information with the researchers' prior information on the coefficients (priors) to derive a posterior distribution. The choice of the prior is an important step of the Bayesian inference since if the prior is too loose, overfitting is hard to avoid; conversely if it is too tight, the data are not allowed to speak. The researchers set the prior according to the information they have on the nature of the parameters of interest or they may use informative priors to reflect their beliefs.

The specification of the priors allows to solve two problems: (a) equations with too many free parameters tend to pick up excess noise, and (b) equations with too few parameters fail to pick up the signal. The usage of the priors provides a flexible solution to the trade-off between less overfitting data and more signal extraction capabilities. Moreover, many studies (Bambura et al 2010; Auer 2014) have confirmed that the B-VAR methodology can be used with success for large datasets as well as for datasets with a moderate level of cointegration.

The Bayesian methods use the maximum likelihood function to estimate the posterior probabilities. This function in other domains can overcome limitations of the techniques such as the generalized method of moments (GMM) of Arellano and Bond (1991). Following Allison et al. (2017) the 
maximum likelihood function changes how the structural estimation models (SEM) perform, allowing accurate estimations.

In the rest of this section we introduce the Litterman-Minnesota prior (Litterman 1986) and the Normal Inverse Wishart prior used in our study.

We start from a standard $\operatorname{VAR}(q)$ model:

$$
Y_{t}=c+A_{1} Y_{t-1}+A_{2} Y_{t-2}+\ldots \ldots+A_{q} Y_{t-q}+u_{t}
$$

Where $q$ is the maximum lags, $c$ are any constant variables in the model, $Y_{t}$ is a vector of the endogenous variables $(N), A$ are the regression coefficients in matrix form $(N \times N)$ and $u_{t}$ is the white noise error term with a covariance matrix $E\left(u_{t} u_{t}^{\prime}\right)=\psi$.

We can rewrite the VAR equation (1) as a system of multivariate regressions:

$$
Y=X A+U
$$

Where:

(a) $Y_{t}=\left(y_{1}, \ldots \ldots \ldots, y_{T}\right)^{\prime}$. The matrix dimension is $T \times N$ (number of observations $\times$ each dependent variable).

(b) $X=\left(x_{1}, \ldots \ldots \ldots, x_{T}\right)^{\prime}$ with $X_{t}=\left(1, y_{t-1}^{\prime}, \ldots \ldots \ldots, y_{t-q}^{\prime}\right)^{\prime}$. The matrix dimension is $T \times k$ where $k=N P+1$. (number of observations $\times$ each lagged dependent variable).

(c) $A=\left(c, A_{1} \ldots \ldots \ldots, A_{q}\right)^{\prime}$. The matrix dimension is $k \times N$ (number of constant/autoregressive terms $\times$ each lagged dependent variable).

(d) $U=\left(u_{1}, \ldots \ldots \ldots, u_{T}\right)^{\prime}$ collects the error terms. The dimension is $T \times N$ (number of error terms $\times$ each dependent variable).

By applying the Bayesian method to VAR models it is possible to select the priors combined with the likelihood function and to produce a tractable posterior that has generally the same density function of the prior.

In our case the Litterman/Minnesota prior for $\beta$ (the parameter of our interest) is a priori normal conditional upon the variance-covariance matrix $\sum_{e}$. Specifically, the Litterman/Minnesota prior 
assumes that the prior means of $\beta$ are all the same given by the value of the hyperparameter $\mu$ is set close to zero, while the covariance prior is non-zero. However, in some cases $\mu$ is set close to one in order to capture the persistence of the time series.

Then, the first step is to define the nature of the matrix $\sum_{e}$ and replace it with an estimate $\widehat{\sum_{e}}$. In general we have three options to set this matrix: (a) using for each series the estimate of the residual variances by fitting AR(1) models; (b) assuming the variance-covariance matrix to be diagonal where all coefficients, except their own lags (and a possible constant), are equal to zero. This is the more used option as it yields a significant decrease of the computational burden for no relationship among the coefficients of the model's equations; (c) estimating $\sum_{e}$ from a classical VAR model. In general, this last choice is not used because if the number of variables and of lags is large, and we have not enough observations, the variance-covariance matrix might be singular.

After defining the nature of the variance-covariance matrix $\sum_{e}$ (fixed, diagonal and known) we need to specify the prior covariance for $\beta$ considering a set of hyperparameters.

Given a diagonal variance-covariance matrix we select the hyperparameters by specifying four scalars:

(a) $\lambda_{1}$ controls the relative importance of sample and prior information. It represents the overall tightness on the variance of the first lag. Setting $\lambda_{1}$ to a small value implies that the prior information dominates the sample information. On the contrary if $\lambda_{1} \rightarrow \infty$, the prior becomes non-informative and the posterior estimates converge to the unrestricted VAR coefficients.

(b) $\lambda_{2}$ sets the relative importance for the lags of the other variables (i.e. lagged variable $i$-th in $j$-th equation with $i \neq j$ ).

(c) $\lambda_{3}$ regulates the relative importance of the information contained in the exogenous variables (i.e. a constant).

(d) $\lambda_{4}$ captures the lag decay and it takes into account the different scale and variability of the data. Setting $\lambda_{4}$ equal to 1 implies a linear decay while if we set greater than zero we have two functional forms: harmonic or geometric decay. 
Once the prior covariance is set, the posterior of $\beta$ will also be normal. In particular the mode and the mean will correspond to a normal.

Although the Litterman/Minnesota is actively used for its success in forecasting, it ignores any uncertainty associated with the variance-covariance matrix. The Normal Inverse Wishart prior relaxes the assumption of a fixed and diagonal variance-covariance matrix of the error terms, therefore overcoming the two main weaknesses in the Litterman prior: the posterior independence between equations and the fixed residual variance-covariance matrix.

Moreover, it is easy to interpret and to calculate, since, the posterior distribution follows the same parametric form of the prior distribution and therefore the prior information can be interpreted in the same way as the likelihood function information.

The Normal-Wishart prior represents a natural conjugate prior for the variance-covariance matrix $\sum_{e}$ that with a prior of $\beta$ set to a normal result in a posterior for $\beta$ equal to the product of a Normal and a Wishart distribution. In this case the prior of $\beta$ depends on the prior means of $\beta$ matrix terms and $\sum_{e}$. For $\sum_{e}$ we select the hyperparameter $\lambda_{1}$ that works in the same way of the Minnesota prior. Moreover, we need to select the two parameters $v$ and $S$ that are respectively the degrees of freedom parameter $(v)$ and the identity matrix $(S)$.

\section{Data}

Our dataset contains the following annual macro-variables: nominal gross domestic product per capita (GDPN) as an economic indicator, nominal health expenditure per capita (HEX) as healthcare indicator, life expectancy (LFE) and ageing index (AI) as demographic and health indicators. Following Lopreite and Mauro (2017) we compute ageing index (AI) as the ratio between the number of people aged 65 or over and the number of people aged from $0-14$. Since the numerator (the size of elderly population is increasing) and the denominator (the size of young population is decreasing due to declines in fertility) of AI vary in the opposite direction, the overall indicator rises over time. Life 
expectancy (LFE) is also a relevant indicator that reflects people's health status as a result of their standard of living, lifestyle, education, way to eat, sport practice etc. According to the World Bank definition, life expectancy at birth is the average number of years a newborn is expected to live if mortality patterns at the time of its birth remain constant in the future. We use the total value (male plus female) of this indicator.

Finally, we use nominal GDP as a measure of income, and nominal health expenditure as a measure of the consumption of healthcare products and services. Both indicators are expressed in per capita value.

The sample spans from the year 1978 to the year 2016 due to data availability. Note that this period of time observed China's rapid economic growth and demographical structure change since China's economic reform of 1978. The data of nominal GDP per capita (GDPN), ageing index (AI), and life expectancy (LFE) are obtained for both China and the USA from the World Bank Development Indicators Database. The data of nominal health expenditure per capita (HEX) are extracted for the USA from the OECD database while for China are extracted from the China Statistical Yearbook. We convert nominal health expenditure per capita in China into US dollars using the RMB-dollar exchange rates contained in the China Statistical Yearbook. Finally, we apply the logarithms to GDPN and HEX in order to reduce the dimensional effects and to minimise the linearisation and the normalisation requirements.

As we can see in Table 1 the USA shows a much higher average value of GDPN and of HEX while the difference between China and the USA in AI and LFE is not as significant. We also notice that the standard deviation of AI and of LFE is higher in China than in the USA.

These findings suggest that, given the lower average values of the Chinese HEX and GDPN, AI and LFE may lead to more constraints on health spending and economic growth in China than in the USA.

Table 1: Summary statistics

China USA

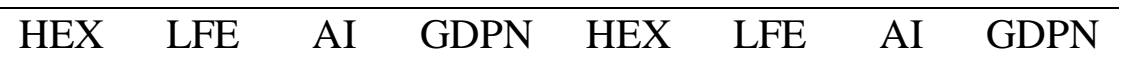




\begin{tabular}{ccccccccc}
\hline Mean & 99.36 & 71.37 & 29.45 & 1943.6 & 4819.3 & 76.30 & 59.28 & 32893 \\
Median & 31.26 & 70.75 & 24.66 & 781.75 & 4145 & 76.42 & 57.63 & 31573 \\
Max & 504.49 & 76.25 & 57.19 & 8117.3 & 10410 & 78.84 & 78.99 & 57589 \\
Min & 6.80 & 65.86 & 11.85 & 156.40 & 865 & 73.35 & 47.62 & 10587 \\
St. dev & 141.62 & 3.16 & 13.80 & 2506.2 & 2931.6 & 1.71 & 6.7 & 14310 \\
\hline
\end{tabular}

\section{B-VAR Analysis: Impulse Response Functions and Forecast Error Variance Decomposition Functions}

In this section we analyse the impulse response functions (IRFs) as well as the forecast error variance decomposition functions (FEVDs) based on the B-VAR model for China and compare the results with those for the USA.

To this end, we estimate the B-VAR model with two lags selected according to the Schwartz Bayesian criterion. The model is specified by considering nominal gross domestic product per capita (GDPN), nominal health expenditure per capita (HEX), life expectancy (LFE), ageing index (AI) and a constant. We select the four hyperparameters of the Minnesota prior covariance matrix as follows: $\lambda_{1}$ (prior information) is set to a small value since the prior beliefs influence the estimation with respect to the information contained in the data; $\lambda_{2}$ (cross variables lags) and $\lambda_{3}$ (exogenous variables) are set greater than zero because the information of cross variable lags and of the exogenous variables is important for our analysis; $\lambda_{4}$ (lag decay) is set greater than zero since the variables are similar in their scale, we assume a geometric decay.

The reasons why we apply the Minnesota prior specification are threefold: firstly, in our analysis we use series in levels and the Minnesota's performance is optimal with this type of macro-variables; secondly, using the levels of the time series we can capture, by analysing the IRFs and the FEVDs, the dynamic information on the relations among the variables (in the short and medium-run); thirdly we obtain estimation gains with respect to an unrestricted VAR since the Minnesota prior shrinks the estimated coefficients of the VAR model towards the prior mean and away from the OLS estimates. 
Figure 1 and Figure 2 depict the IRFs for the B-VAR model for China and the USA side by side for the four variables (GDPN, HEX, LFE, AI). The shaded regions indicate the posterior coverage intervals corresponding to the $95 \%$ of the Bayesian credible sets obtained through Gibbs sampling using 1000 iterations. 
Figure 1: B-VAR impulse response functions with $95 \%$ credible intervals for China and the USA side by side for ageing index (AI) shock and life expectancy (LFE) shock (10-year horizon; nominal variables)
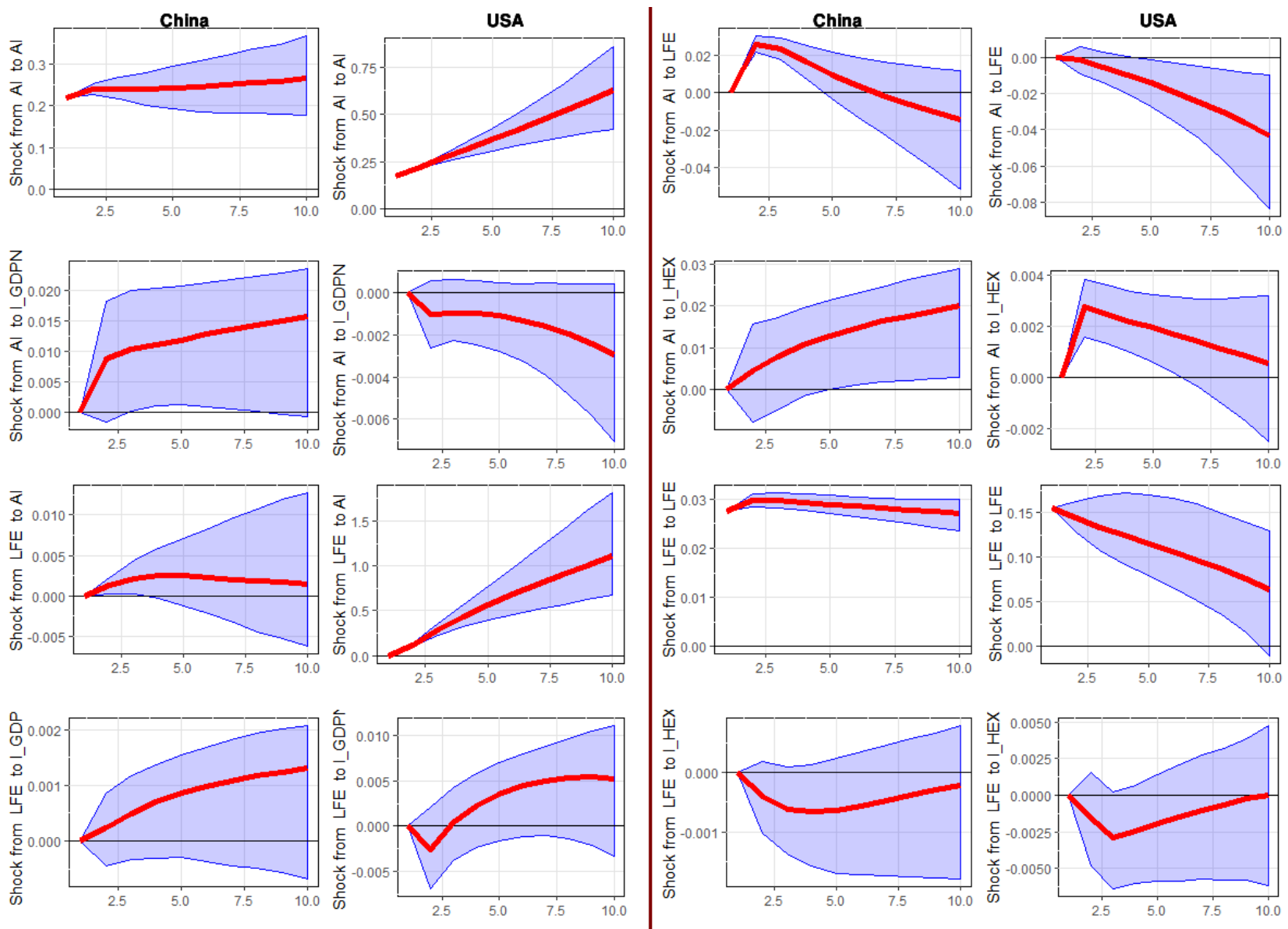
Figure 2: B-VAR impulse response functions with $95 \%$ credible intervals for China and the USA side by side for nominal gross domestic product per capita (GDPN) shock and health expenditure per capita (HEX) shock (10-year horizon; nominal variables)
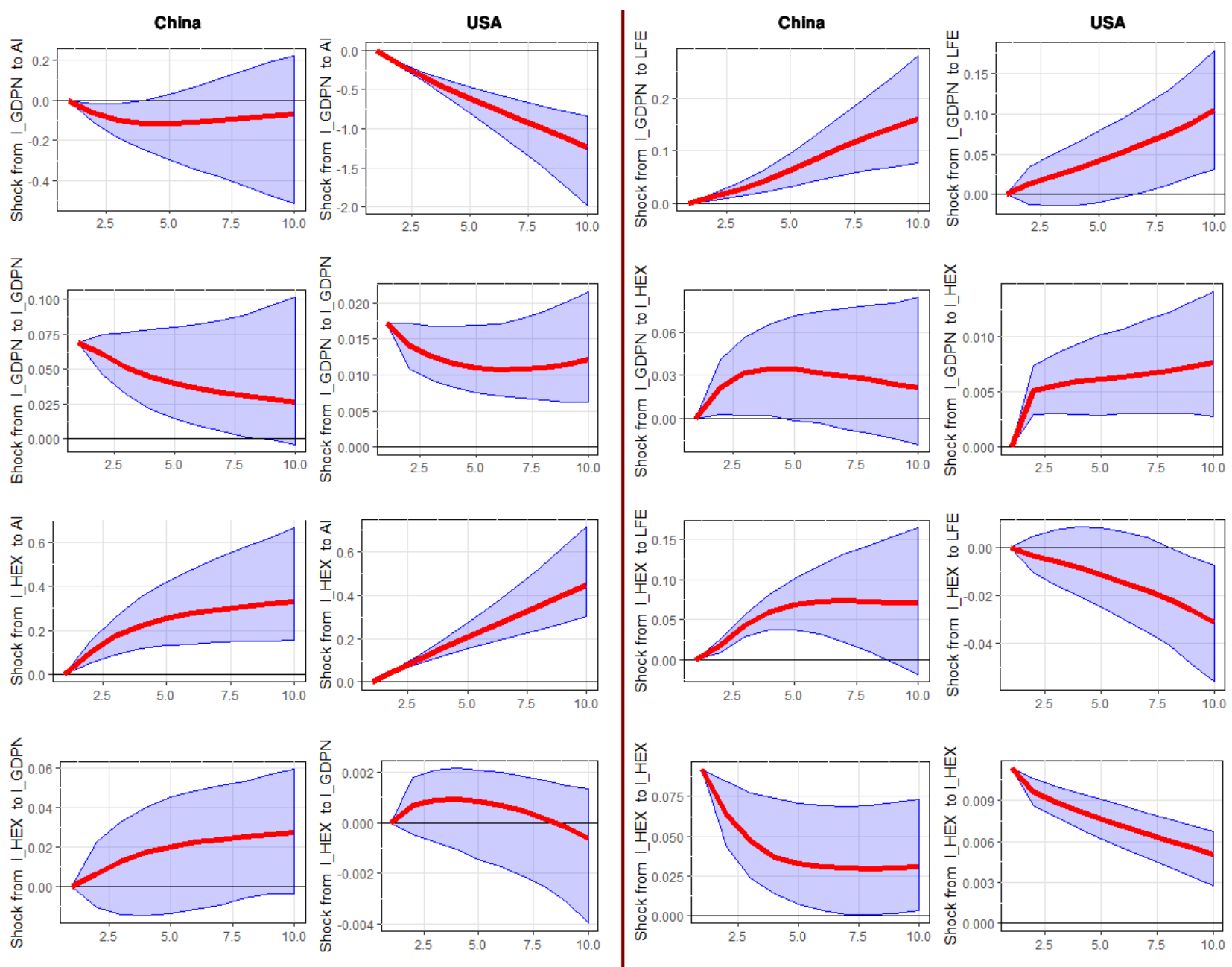
We present the responses of a variable to a shock (one standard deviation) from each of the other variables for the B-VAR model until ten years when this effect becomes less significant. In particular we study whether there exist or not significant relationships between nominal gross domestic product per capita (GDPN), nominal health expenditure per capita (HEX), life expectancy (LFE) and ageing index (AI) and what the directions of causality are. As a robustness check, we also extend the horizon of the IRFs from ten to twenty years and the new IRFs for both China and USA converge to zero or to a constant level. This suggests the absence of explosive functions like exponential IRFs that do not converge to zero or constant levels given unstable causal relationships (see Figures A2 and A3 in the appendix).

For China a LFE shock raises AI approximately of $0.5 \%$ after 2.5 years and it becomes not significant after 4 years (third row, first column, Figure 1). At the same time, AI has also a positive effect on GDPN that remains significant for the years 3-7 (with a peak around 1.2\% after 5 years) while on HEX the effect becomes significant after 5 years and it is increasing in the long run (with a peak around $2 \%$ after 7.5 years) (second row, first and third column, Figure 1). On the other hand, GDPN has a positive and significant impact on LFE (first row, third column, Figure 2), whereas its impact on HEX is only slightly positive and becomes not significant after 5 years (second row, third column, Figure 2). Finally, more HEX leads to an increase that is persistent in time for both LFE (by 0.8 after 5 years) and AI (by 0.3 after 2.5 years) (third row, third and first column, Figure 2). To better understand the patterns found for China, we also estimate a B-VAR model for the USA for the same period of time as a comparison. We observe a significant and positive response that becomes persistent in the long term respectively from HEX to a GDPN shock (second row, fourth column, Figure 2), from LFE to AI (third row, second column, Figure 1) and from AI to an HEX shock (third row, second column, Figure 2). Moreover, we find a weakly negative effect only in the long run of an HEX shock on LFE (third row, fourth column, Figure 2). We also observe a positive and very weak long run effect of a GDPN shock on LFE (first row, fourth column, Figure 2). Finally, we observe a temporary and weak impact of AI on HEX: the short-lived effect becomes insignificant 
after 6 years (second row, fourth column, Figure 1). Unlike the finding for China, the effect of an AI shock on GDPN is not significant for the USA (second row, second column, Figure 1).

To further understand the relative importance of each variable in affecting other variables, we compute the forecast error variance decomposition functions (FEVDs) for China and the USA side by side for the same time horizon of ten years (Figures 3 and 4), which confirm the robustness of the above results. Specifically, for China we find a moderate contribution of AI (around 2\%) to the variance of GDPN (second row, first column, Figure 3). We also observe a significant impact of AI (around 3\%) on HEX (second row, third column, Figure 3), of GDPN (around 2.5\%) on HEX (second row, third column, Figure 4) and of GDPN (around 75\%) on LFE (first row, third column, Figure 4). On the other hand, for the USA GDPN has accounted for about 70\% of HEX's forecast error variance after 10 years (second row, fourth column, Figure 4). Moreover, we find a significant influence (around 30\%) of LFE on AI (third row, second column, Figure 3) and of GDPN (around 60\%) on AI (first row, second column, Figure 4). Finally, we observe a moderate contribution of AI (around 1\%) to HEX's variance (second row, fourth column, Figure 3). 
Figure 3: B-VAR forecast error variance decomposition functions with $95 \%$ credible intervals for China and the USA side by side for ageing index (AI) shock and life expectancy (LFE) shock (10year horizon; nominal variables)
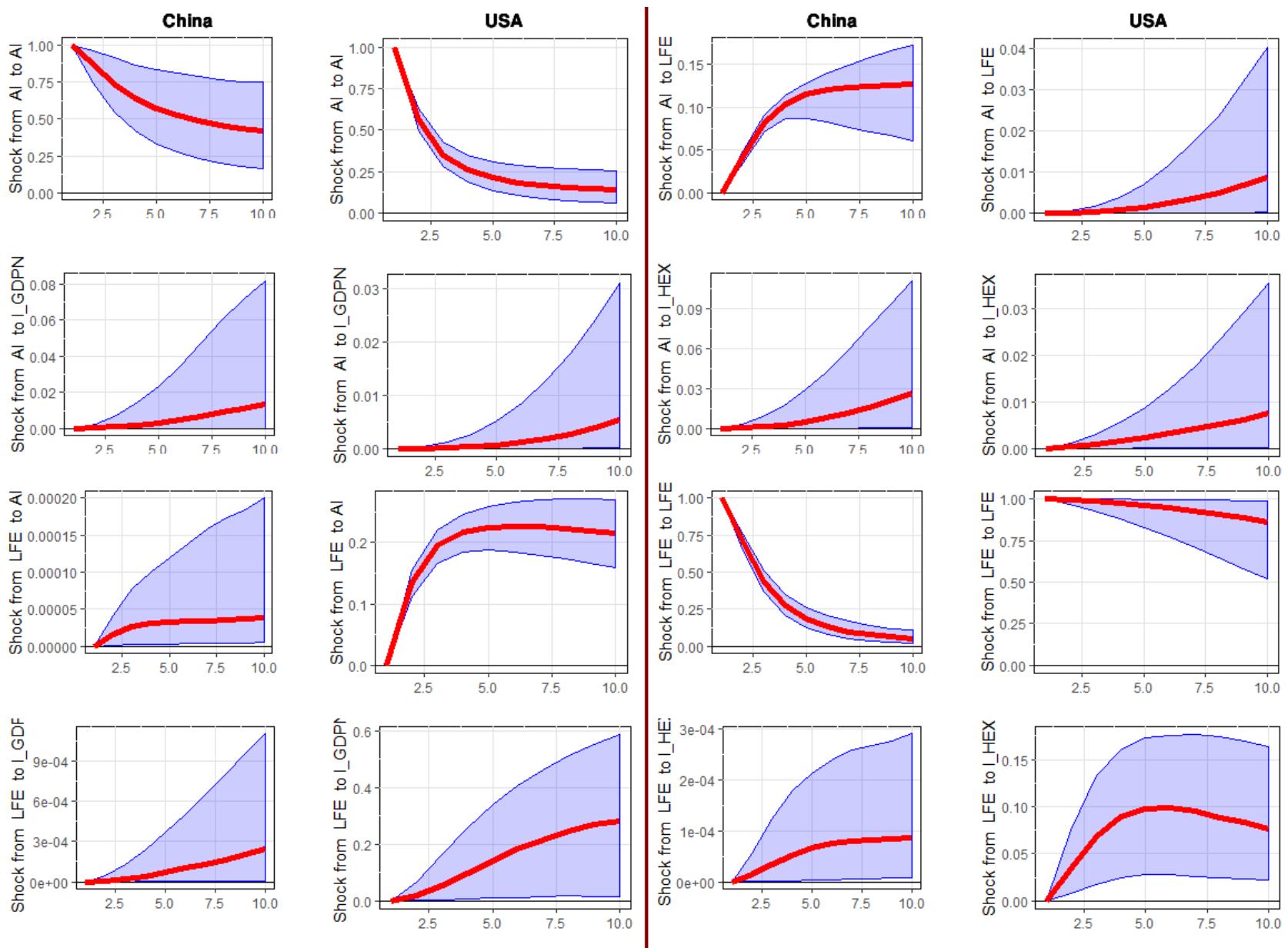
Figure 4: B-VAR forecast error variance decomposition functions with $95 \%$ credible intervals for China and the USA side by side for nominal gross domestic product per capita (GDPN) shock and health expenditure per capita (HEX) shock (10-year horizon; nominal variables)
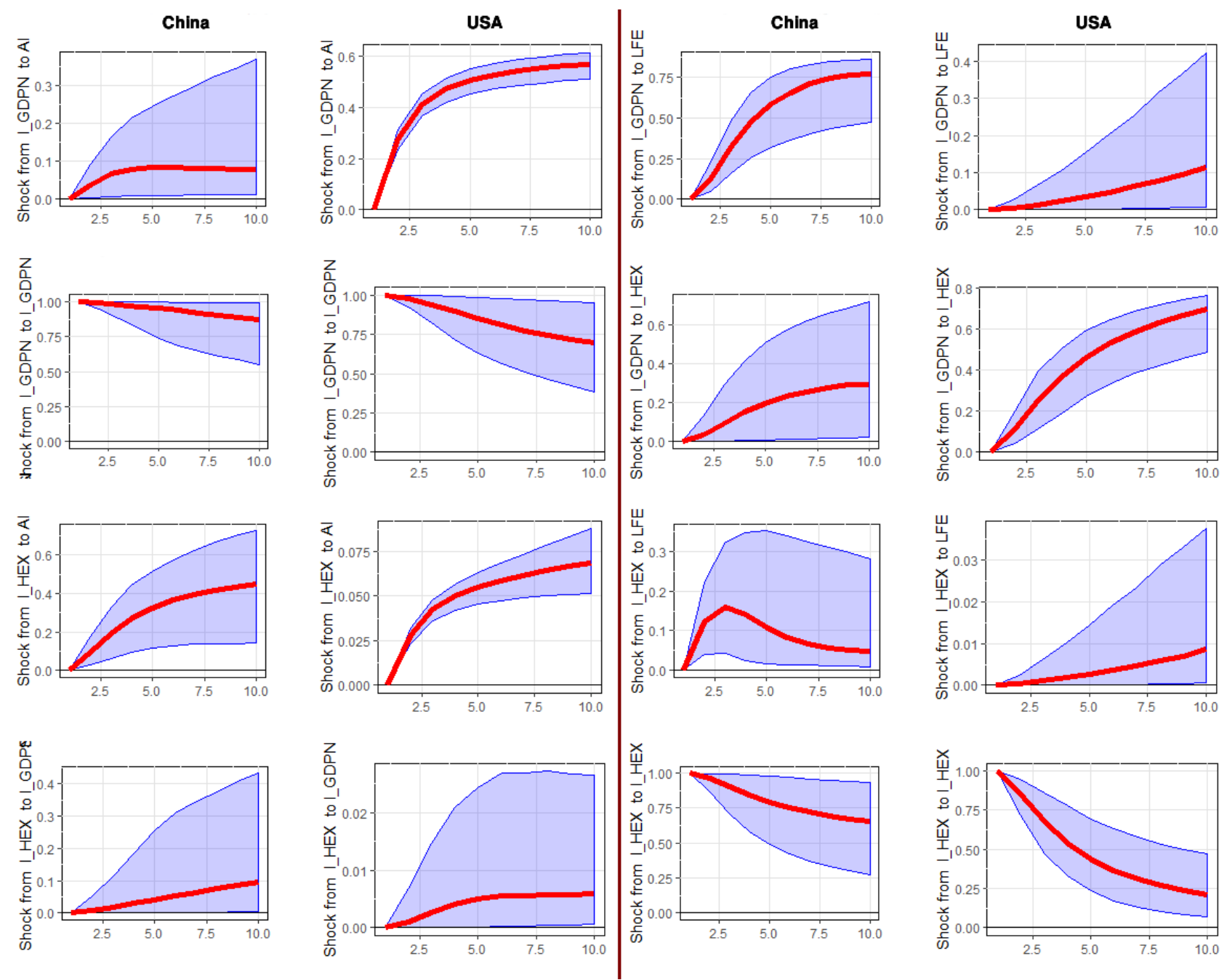
The comparison between China and the USA can be summarised as follows. For China, LFE, GDPN and AI have relatively strong impacts on the other variables, whereas in the USA, HEX and GDPN are the major drivers, as shown in the IRFs results. This means that GDPN plays an important role in the macro systems for both countries. However, compared with the situation in China, in the USA, life expectancy (LFE) and ageing population (AI) have relatively small impacts on the other variables. In other words, these findings suggest that the increasing share of elderly population has a greater impact on China than to the USA.

\section{Forecast Evaluation}

To evaluate the performance of our model, in this section we empirically compare the forecast accuracy resulted from two different VAR specifications (unrestricted VAR model and B-VAR models based respectively on the Minnesota prior and on the Normal-inverse-Wishart prior) for our dataset of both China and the USA over the period 1978-2016.

We compute the point forecasts (two year ahead) using the Root Mean Square Error (RMSE) and the Mean Absolute Error (MAE) to select which model specification has the best forecast accuracy. More precisely:

$\operatorname{RMSE}=\sqrt{\frac{\sum_{i}^{n}\left(y_{i}-\overline{y_{l}}\right)^{2}}{n}}$

MAE $=\frac{\sum_{i}^{n}\left|y_{i}-\bar{y}_{l}\right|}{n}$

where $y_{i}$ are the data and $\overline{y_{l}}$ is the forecast value of $y_{i}$.

We prefer to use both measures because RMSE is more sensitive to large deviations from the true values while MAE is more sensitive to small deviations from the true values.

A small value of RMSE, and of MAE suggests a good performance of the model. Table 2 presents the results for China and the USA. The findings show that the B-VAR models based on Minnesota prior fit better than the VAR model and the B-VAR model based on the Normal-inverse-Wishart 
prior. Overall, the prior information improves the forecast accuracy of the B-VAR models with respect to other specifications (VAR model).

Table 2: A comparison between USA model and China model: Forecasting VAR vs B-VAR (nominal variables)

\begin{tabular}{|c|c|c|c|}
\hline & Variable & RMSE & MAE \\
\hline \multicolumn{4}{|l|}{ USA model } \\
\hline \multirow{4}{*}{ Standard VAR } & LFE & 0.272 & 0.272 \\
\hline & AI & 0.102 & 0.102 \\
\hline & GDPN & 0.028 & 0.028 \\
\hline & HEX & 0.120 & 0.121 \\
\hline \multirow{4}{*}{ Minnesota prior } & LFE & 0.111 & 0.101 \\
\hline & AI & 0.055 & 0.055 \\
\hline & GDPN & 0.026 & 0.025 \\
\hline & HEX & 0.065 & 0.065 \\
\hline \multirow{5}{*}{$\begin{array}{l}\text { Normal-Wishart } \\
\text { prior }\end{array}$} & LFE & 0.263 & 0.260 \\
\hline & AI & 0.057 & 0.056 \\
\hline & GDPN & 0.029 & 0.029 \\
\hline & HEX & 0.066 & 0.120 \\
\hline & Variable & RMSE & MAE \\
\hline \multicolumn{4}{|l|}{ China model } \\
\hline \multirow{4}{*}{ Standard VAR } & LFE & 0.253 & 0.256 \\
\hline & AI & 0.043 & 0.045 \\
\hline & GDPN & 0.294 & 0.316 \\
\hline & HEX & 0.311 & 0.308 \\
\hline \multirow{4}{*}{ Minnesota prior } & LFE & 0.250 & 0.249 \\
\hline & AI & 0.042 & 0.043 \\
\hline & GDPN & 0.203 & 0.207 \\
\hline & HEX & 0.124 & 0.288 \\
\hline \multirow{4}{*}{$\begin{array}{l}\text { Normal-Wishart } \\
\text { prior }\end{array}$} & LFE & 0.370 & 0.366 \\
\hline & AI & 0.052 & 0.054 \\
\hline & GDPN & 0.377 & 0.384 \\
\hline & HEX & 0.385 & 0.389 \\
\hline
\end{tabular}

\section{Further Robustness Checks}

We further check the robustness of the results by repeating the analysis for the same time span (19782016) and for both countries with real variables (i.e., real GDP per capita and real health expenditure 
per capita). To do so, we deflate the time series of nominal GDP per capita and nominal health expenditure per capita with constant prices in 2010 for both countries.

A B-VAR model is therefore estimated to test the relations between real GDP per capita (GDPR), real health expenditure per capita (HEXR), aging index (AI) and life expectancy (LFE). The results remain qualitatively unchanged. In particular, the IRFs based on the B-VAR model with the horizon of twenty years yield a significant response for both the USA and China of AI to LFE and of HEXR to GDPR. As before, we also observe that AI has a stronger impact on HEXR and GDPR in China than in the USA (Figures 5-6). These relations are again confirmed by the results of FEVDs (Figures 7-8).

We also run diagnostics of the model with respect to the requirements of absence of serial autocorrelation, and structural stability of the parameters estimated (the results are available on request). The results obtained therefore confirm the analysis of the IRFs and the FEVDs of the BVAR model previously estimated with nominal variables. Finally, the forecast accuracy of the BVAR model is again the highest among all the specifications (Table A1 in the appendix). 
Figure 5: B-VAR impulse response functions with $95 \%$ credible intervals for China and the USA side by side for ageing index (AI) shock and life expectancy (LFE) shock (20-year horizon; real variables)
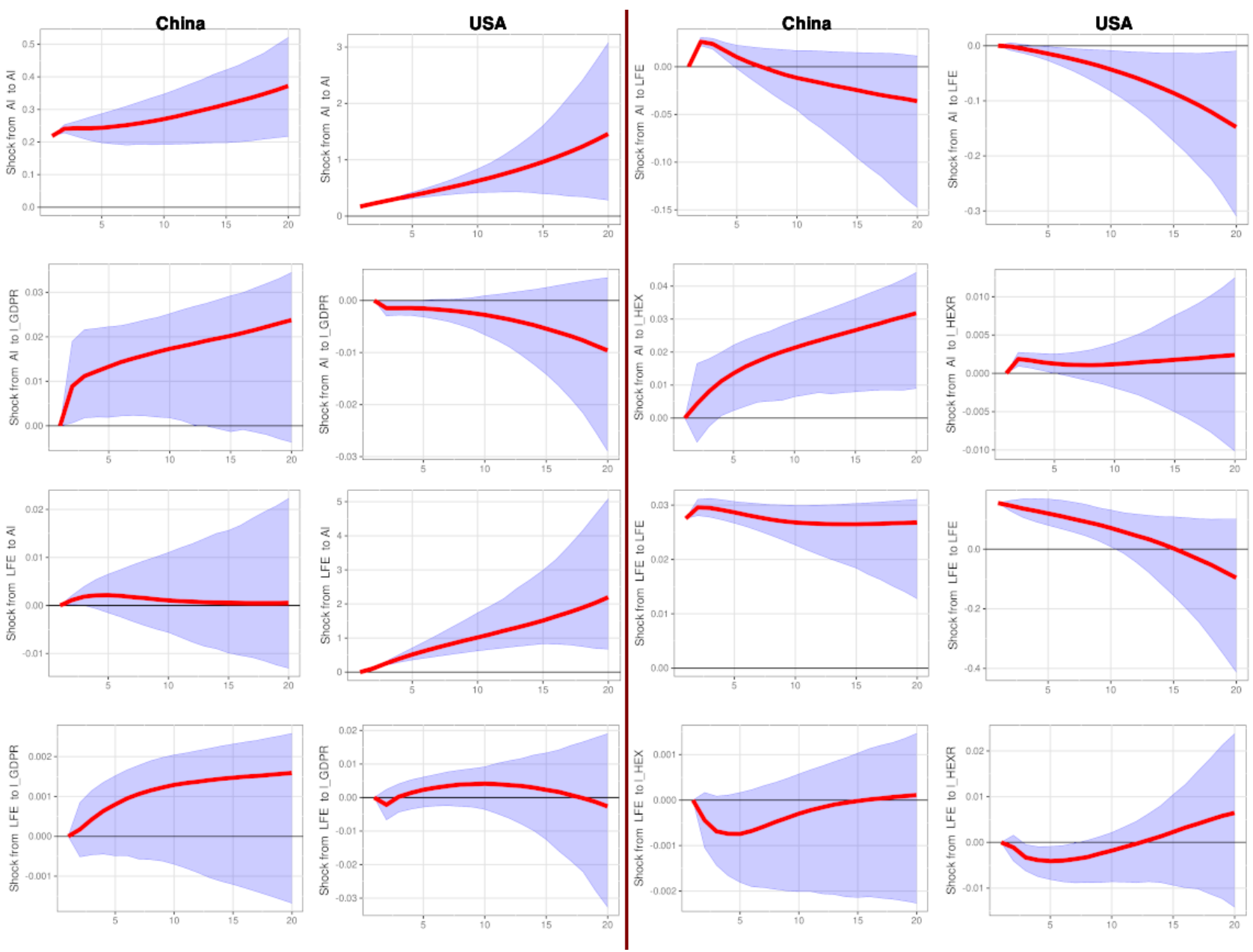
Figure 6: B-VAR impulse response functions with $95 \%$ credible intervals for China and the USA side by side for real gross domestic product per capita (GDPR) shock and real health expenditure per capita (HEXR) shock (20-year horizon; real variables)
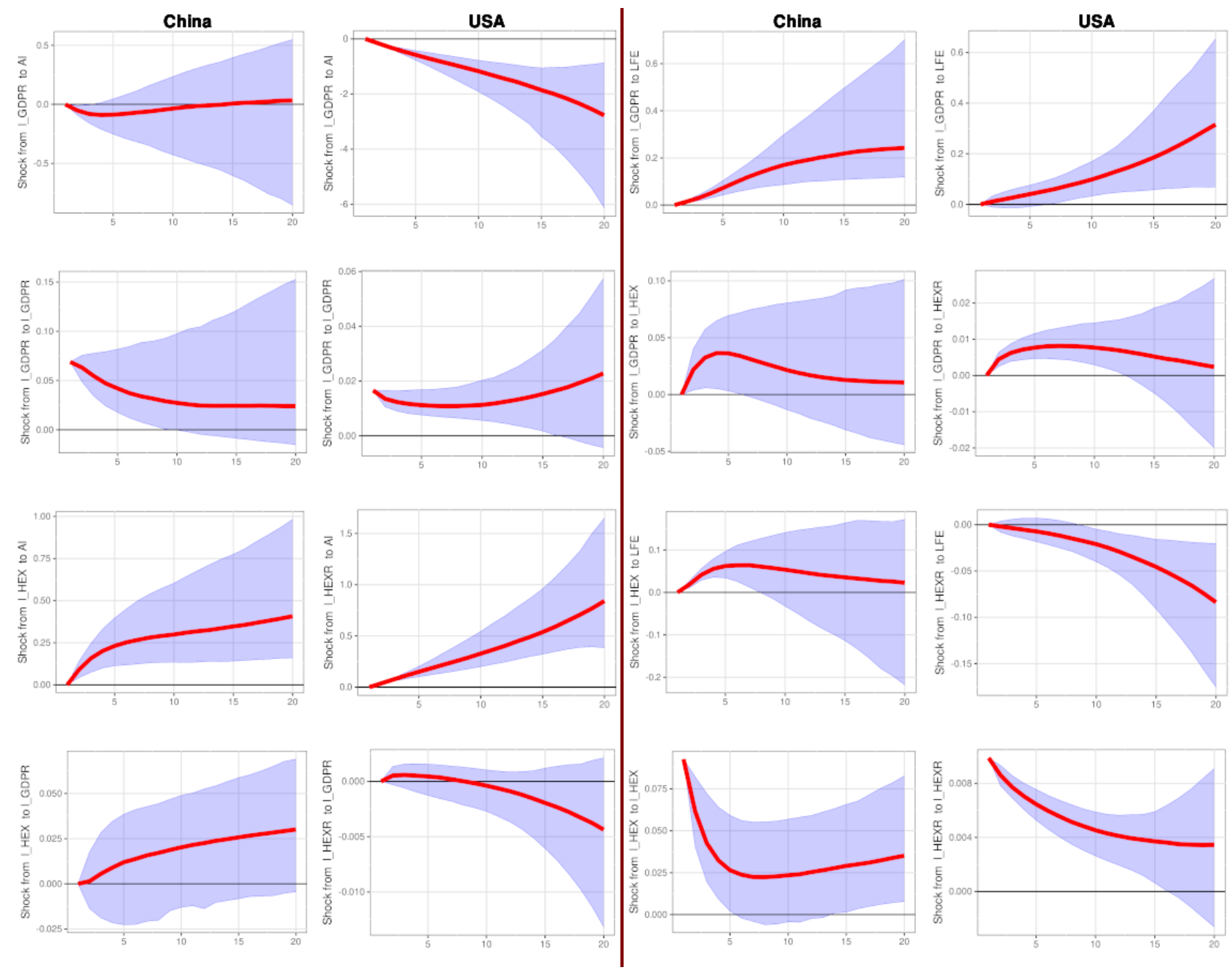
Figure 7: B-VAR forecast error variance decomposition functions with $95 \%$ credible intervals for China and the USA side by side for ageing index (AI) shock and life expectancy (LFE) shock (20year horizon; real variables)
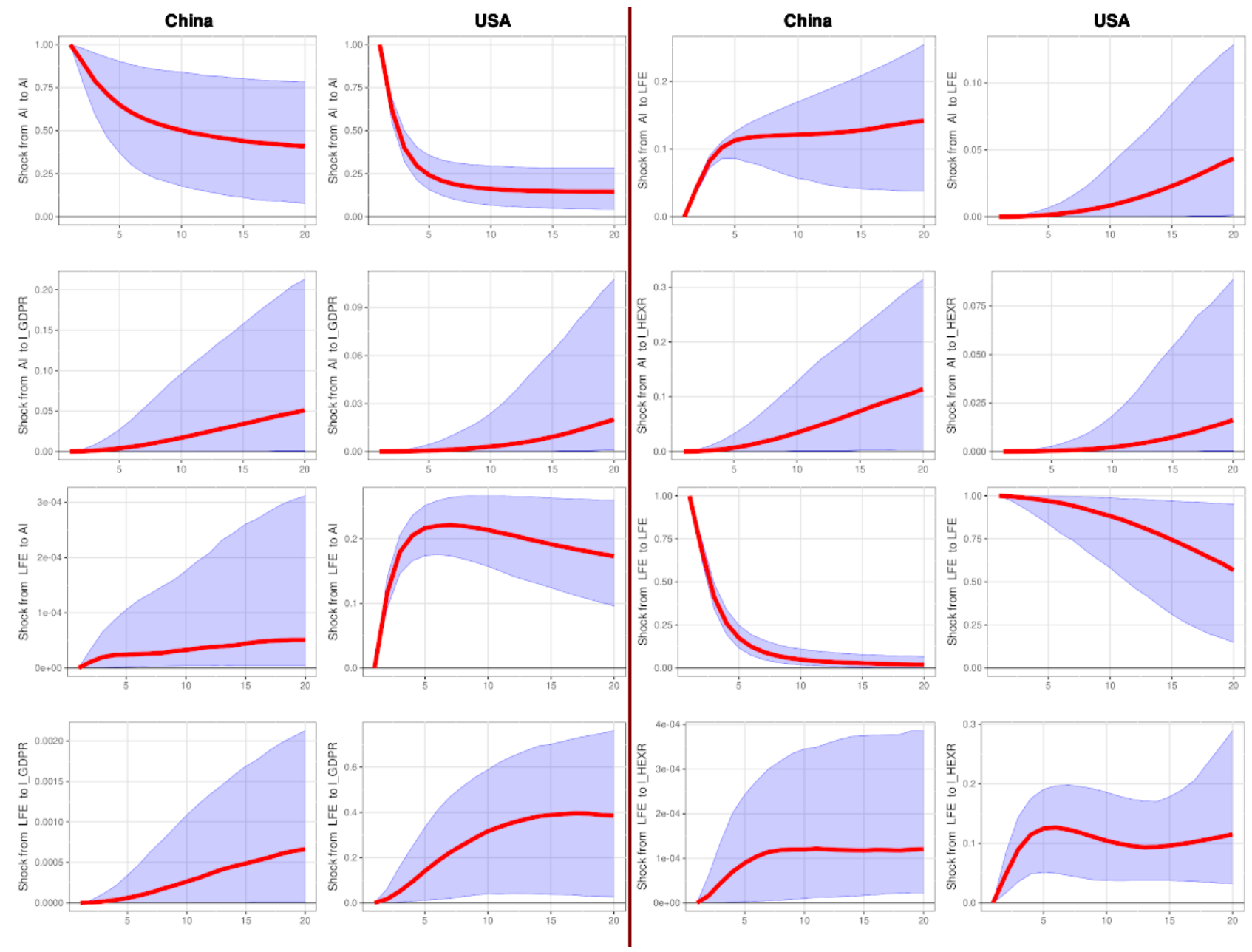
Figure 8: B-VAR forecast error variance decomposition functions with $95 \%$ credible intervals for China and the USA side by side for real gross domestic product per capita (GDPR) shock and real health expenditure per capita (HEXR) shock (20-year horizon; real variables)
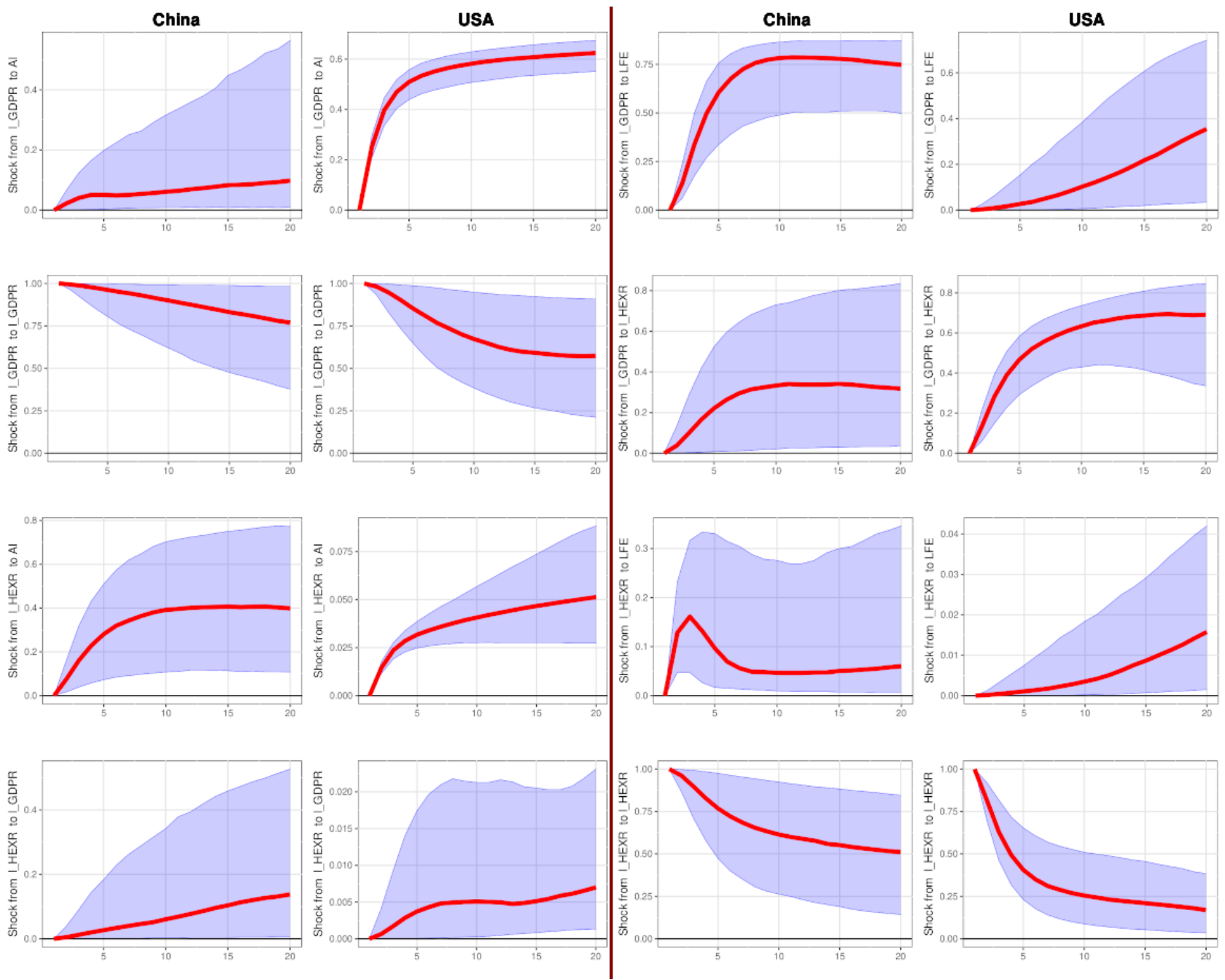

\section{Conclusions and Policy Implications}

This paper empirically examines the relationships between ageing index, life expectancy, economic growth and health spending in China. We compute the impulse response functions (IRFs) and the forecast error variance decomposition functions (FEVDs) based on the Bayesian-VAR (B-VAR) model for China over the period 1978-2016. The B-VAR model is preferred over others for three reasons: (a) it is an appropriate choice for handling short time series data (i.e., with a small number 
of years); (b) it naturally incorporates judgmental information and a priori beliefs into the model settings; (c) it performs better in terms of forecasting accuracy than a classical VAR model.

Unlike the existing literature where empirical relationships are examined one at a time, this paper considers the relationships between ageing index, life expectancy, economic growth and health spending and all the possible directions of causality simultaneously using standard B-VAR specifications. We set the priors following standard recommendations from the Bayesian literature and take into account the data characteristics. The results suggest that the Minnesota prior information is important for the dynamical analysis as well as for the forecasting accuracy. In particular, it produces better forecasting results than the VAR models or the B-VAR models based on Normal Inverse Wishart prior.

Furthermore, with a comparison with the USA for the same period of time, we have found the following main results: (a) economic growth generally promotes health spending and an increase in life expectancy leads to an increase in ageing index in both China and the USA; (b) the importance of ageing index in health expenditure and in GDP is larger in China. These findings suggest that China is more affected by population ageing in the observation period from 1978-2016.

Not only do China and the USA differ from each other in terms of the importance of AI measured by FEVDs, but the two countries also differ in the timing of AI-triggered GDPN and HEX responses measured by the IRFs. In particular, China has a positive medium-run significant impact of AI on GDPN whereas the impact for the USA is negative and insignificant. China has a positive and significant impact of AI on HEX in the long-run whereas the impact for the USA is also positive and significant but in the short-run.

To make sure that our results are not driven by price factors during this period of time, we further check the robustness of the results by repeating the analysis with real GDP per capita and real health expenditure per capita. The results indeed remain qualitatively unchanged.

Our results are in line with the predictions by Bloom et al. (2010a) in a sense that population ageing induces a more negative effect on economic growth for developed countries than for developing 
countries. However, there are notable differences between the decomposition analyses of the effects of population ageing on economic growth in the existing literature (Bloom et al. 2010a, 2010b, Mason and Lee, 2007) and ours. Firstly, the previous decomposition analyses are based on economic growth accounting (i.e., decomposing economic growth rates into demographic growth rates and others) whereas ours are based on an empirical model B-VAR and the related computation of FEVDs. The FEVDs show the amount of information that each variable contributes to the other variables in the model. It determines how much of the forecast error variance of each of the variables can be explained by exogenous shocks to the other variables. Our FEVDs analysis is useful to determine which of the independent variables is "stronger" in explaining the variability in the dependent variables over time. Secondly, rather than using counterfactual exercises or simulations, this paper is empirically driven by actual data and hence provides solid evidence of the different economic reactions to population ageing between the largest developing economy and the largest developed economy in the world. The differences observed above between China and the USA are clearly linked to the different dynamics of population age structure and economic development experienced in the past four decades by the two countries. The rapid growth of the proportion of the elderly has led China to "become old before getting rich" and to lose its "first demographic dividend" (Cai, 2010). On the contrary, the USA, as a developed country, has possessed a mature social and economic system while supporting its ageing population (see Figure A1 in the appendix). While an AI shock still triggers a positive and significant response from GDPN in China in the medium-run, it is unlikely to sustain in the coming decades given that China's economic growth has already slowed down.

On the other hand, the medium-run significant response of HEX to AI shocks is more worrisome for China. One way to cut the health expenditure in China is to establish a fully functioning three-tier healthcare system, where the role of primary healthcare providers as a gatekeeper is of critical importance (Li et al. 2017, Xu and Mills 2019, Yu 2015, Yip et al. 2019). Moreover, a sounding health infrastructure cannot live without sustainable financial schemes. In this regard, China has made promising progresses for both urban and rural populations (Hsiao 1995, Feng et al. 2020, Gao et al. 
2014). Another solution, as emphasised by Bloom et al. (2010a), is to encourage behavioural adjustments. For instance, community programmes can be developed to help the elderly maintain their economic activities by providing training and employment opportunities, flexible working hours and remuneration even after their retirement. More generally, a retirement reform requires a comprehensive policy package effectively addressing a host of factors including replacement rate of pension, personal life events, savings, work condition, health, and family circumstances rather than merely postponing the retirement age (Liu and Sun, 2016).

Resulted from an evidence-based approach, the findings presented here are clearly informative for supporting healthcare policy decisions. But to devise or evaluate a specific healthcare policy, it certainly requires detailed investigation, especially at micro level, as the aggregated variables considered here cannot be directly translated into policy instruments. Another limitation of this study is that only a short period of time from 1978-2016 and only two countries are considered here. The limitation can be addressed in the future with larger data sets with longer time series or more countries, which are desirable for further testing the robustness of the results and for generalising the policy implications for both developed and developing countries. These issues are left for future investigation. 


\section{References}

Allison P.D., Williams R., Benito E.M., (2017). Maximum Likelihood for Cross-lagged Panel Models. Socius: Sociological Research for a Dynamic World,3,1-17. https://doi.org/10.1177/237802311771057

Álvarez-Gálvez,J.;Jaime-Castillo,A.M(2018). The impact of social expenditure on health inequalities in Europe. Social Science \& Medicine, 200,9-18.

Amiri, A.; Ventelou, B. (2012). Granger causality between total expenditure on health and GDP in OECD: Evidence from the Toda-Yamamoto approach. Economics Letters, 116(3),541-544.

Amiri,A.; Linden,M.(2016) Income and total expenditure on health in OECD countries: Evidence from panel data and Hsiao's version of Granger non-causality tests. Economics and Business Letters,5(1),1-9.

Arellano, M., \& Bond, S. (1991). Some tests of specification for panel data: Monte Carlo evidence and an application to employment equations. The review of economic studies, 58(2), 277-297. Auer S(2014). Monetary Policy Shocks and Foreign Investment Income: Evidence from a large Bayesian VAR, SNB Working Papers 2/2014.

Baltagi,B.H.;Moscone ,F.(2010) Health care expenditure and income in the OECD reconsidered: Evidence from panel data. Economic modelling,27(4),804-811.

Banbura M, Giannone D, Reichelin L(2010). Large Bayesian VARs. Journal of Applied Econometrics, 25, 71-92.

Beckworth, D., \& Hendrickson, J. R. (2020). Nominal GDP targeting and the Taylor rule on an even playing field. Journal of Money, Credit and Banking, 52(1), 269-286.

Bloom, D.E.; Canning, D.; Fink, G.(2010a). Implications of population ageing for economic growth. Oxford Review of Economic Policy,26(4),583-612.

Bloom, D. E., Canning, D., Hu, L., Liu, Y., Mahal, A., \& Yip, W. (2010b). The contribution of population health and demographic change to economic growth in China and India. Journal of Comparative Economics, 38(1), 17-33. 
Bloom,D.E.;Chatterji,S.;Kowal,P.;Lloyd-Sherlock,P.;McKee,M.;Rechel,B.;Rosenberg,L.;Smith,J.P. (2015). Macroeconomic implications of population ageing and selected policy responses. The Lancet, 385(9968),649-657.

Bloom, D. E., \& Williamson, J. G. (1998). Demographic transitions and economic miracles in emerging Asia. The World Bank Economic Review, 12(3), 419-455.

Braendle, T.; Colombier, C (2016).What drives public health care expenditure growth? Evidence from Swiss cantons,1970-2012..Health Policy,120(9),1051-1060.

Breyer,F.;Felder,S. (2006). Life expectancy and health care expenditures: a new calculation for Germany using the costs of dying. Health policy,75(2),178-186.

Cai, F. (2010). Demographic transition, demographic dividend, and Lewis turning point in China. China Economic Journal, 3(2), 107-119.

Cai, F. (2012). Is There a "Middle-income Trap"? Theories, Experiences and Relevance to China. China \& World Economy, 20(1), 49-61.

Canova, F.(2007). Bayesian VARs. in Methods for Applied Macroeconomic Research. Princeton University Press.

Chaabouni, S.; Zghidi, N.; Mbarek, M.B.(2016) On the causal dynamics between CO2 emissions, health expenditures and economic growth. Sustainable Cities and Society,22,184-191.

Chaabouni,S.;Saidi,K. (2017)The dynamic links between carbon dioxide(CO2)emissions, health spending and GDP growth: A case study for 51 countries. Environmental Research,158,137-144.

Christiano, L. J., Eichenbaum, M. and Evans C. (1999), Monetary policy shocks: What have we learned and to what end? in: J.B.Taylor and M.Woodford eds., Handbook of Macroeconomics, 1, 65147.

China Statistical Yearbook (2015) compiled by National Bureau of Statistics of China.

Choi,K.H.;Shin,S. Population aging, economic growth, and the social transmission of human capital: An analysis with an overlapping generations model. Economic Modelling,50,138-147. 
Doan, T., Litterman, R.B. and Sims, C.A. Forecasting and Conditional Projection Using Realistic Prior Distribution. Econometric Review 1984, 3, 1-100. https://doi.org/10.1080/07474938408800053 Feng, J., Wang, Z., \& Yu, Y. (2020). Does Long-Term Care Insurance Reduce Hospital Utilization and Medical Expenditures? Evidence from China. Social Science \& Medicine, 113081.

Fogel RW (2002). Nutrition Physiological Capital and Economic Growth, Pan America Health Organization and Inter American Development Bank; 2002, available at http://www.paho.org/English/HDP/HDD/fogel.pdf.

Fogel RW (2004). Health, nutrition and economic growth. Economic Development and Cultural Change, 52, 643-58. ABI/INFORM.

Fougère,M.;Mérette,M.(1999). Population ageing and economic growth in seven OECD countries. Economic Modelling, 16(3),411-427.

Fujino,S., (1987). Health Economics in Japan: Prospect for the Future. In: Smith G.T., ed,. Health Economics: Prospect for the Future. London; New York: Croom Helm cited in Huang S.L. (2004). Factors Influencing Healthcare Spending in Singapore: A Regression Model. International Journal of the Computer, the Internet and Management, 12(3), 51-62.

Gallet,C.A.;Doucouliagos,H.(2017). The impact of healthcare spending on health outcomes: A metaregression analysis. Social Science \&Medicine,179,9-17.

Gao, C., Xu, F., \& Liu, G. G. (2014). Payment reform and changes in health care in China. Social Science \& Medicine, 111, 10-16.

Gerdtham, U.G.; Søgaard, J.; Andersson, F.; Jönsson, B. (1992). An econometric analysis of health care expenditure: across section study of the OECD countries. Journal of Health Economics,11(1),6384.

Giannone D, Reichlin L (2006). Does information help recovering structural shocks from past observations? Journal of the European Economic Association vol. 4, issue 2-3, pp. 455-465. Harper,S.(2014). Economic and social implications of aging societies. Science,346(6209),587-591. 
Halící-Tülüce, N.S.; Doğan, İ.; Dumrul, C.(2016). Is income relevant for health expenditure and economic growth nexus? International Journal of Health Economics and Management,16(1),23-49. Hsiao, W. C. (1995). The Chinese health care system: lessons for other nations. Social science \& medicine, 41(8), 1047-1055.

International Monetary Fund (IMF 2012). Growth Resuming, Dangers Remain. World Economic Outlook, April 2012

IMF (2013). The end of Cheap labour. Finance and Development,6, 34-37.

Jaba,E.;Balan,C.B.;Robu,I.B.(2014). The relationship between life expectancy at birth and health expenditures estimated by across-country and time-series analysis. Procedia Economics and Finance, 15,108-114.

Kadiyala KR, Karlsson S. (1997). Numerical methods for estimation and inference in Bayesian VARmodels. Journal of Applied Econometrics 12(2): 99-132.

Kanngiesser, D., Martin, R., Maurin, L., \& Moccero, D. (2019). The macroeconomic impact of shocks to bank capital buffers in the Euro Area. The BE Journal of Macroeconomics.

Kildemoes, H.W.; Christiansen, T.; Gyrd-Hansen, D.; Kristiansen, I.S.; Andersen, M. (2006) The impact of population ageing on future Danish drug expenditure. Health Policy,75(3),298-311.

Koop, G. and Korobilis, D. (2009). "Bayesian multivariate time series methods for empirical macroeconomics," Foundations and Trends in Econometrics, 3, 267-358.

Kunze,L.(2014). Life expectancy and economic growth. Journal of Macroeconomics,39,54-65.

Lee, R., Mason, A., \& Miller, T. (2000). Life cycle saving and the demographic transition: The case of Taiwan. Population and Development Review, 26, 194-219.

Li, X., Lu, J., Hu, S., Cheng, K. K., De Maeseneer, J., Meng, Q., ... \& Krumholz, H. M. (2017). The primary health-care system in China. The Lancet, 390(10112), 2584-2594.

Linden,M.;Ray,D.(2017). Life expectancy effects of public and private health expenditures in OECD countries 1970-2012: Panel time series approach. Economic Analysis and Policy,56,101-113. 
Litterman R.B (1981). A Bayesian Procedure for forecasting with vector autoregressions. In working paper Federal Reserve Bank of Minneapolis.

Litterman R.B. (1986). Forecasting with Bayesian Vector Autoregressions: Five Years of Experience, Journal of Business and Statistics, 4, 25-38.

Liu, T., \& Sun, L. (2016). Pension reform in China. Journal of aging \& social policy, 28(1), 15-28. Lloyd-Sherlock,P.(2000). Population ageing in developed and developing regions: implications for health policy. Social Science \& Medicine,51(6),887-89

Lopreite,M.; Mauro,M.(2017) The effects of population ageing on health care expenditure: a Bayesian VAR analysis using data from Italy. Health policy, 121(6),663-674.

Mason, A., \& Lee, R. (2006). Reform and support systems for the elderly in developing countries: capturing the second demographic dividend. Genus, 11-35.

Mason, A., \& Lee, R. (2007). Transfers, capital, and consumption over the demographic transition. Population aging, intergenerational transfers and the macroeconomy, 128-162.Murthy, N.R.V. and Ukpolo, V.(1994). Aggregate Health Care Expenditure in the United States: Evidence from Cointegration test, Applied Economics 26(8), 797-802.

Murthy, V.N.; Okunade, A.A.(2016) Determinants of US health expenditure: Evidence from autoregressive distributed lag(ARDL)approach to cointegration. Economic Modelling, 59,67-73.

Obrizan, M.; Wehby, G.L.(2018). Health Expenditures and Global Inequalities in Longevity. World Development,101,28-36.

OECD (2017). Health at a Glance. OECD indicators.DOI:https://dx.doi.org/10.1787/health_glance2017-en.

Qiao, H. H. (2006). Will China grow old before getting rich?. Goldman Sachs.

Sims, C.A. (1980). Macroeconomics and reality, Econometrica, 48, 1-48.

Sims, CA.(1982) Policy analysis with Econometrics Models. In: Brookings Papers on Economic Activity, pp. 107-52. 
Sims, C. A. (1992), Interpreting the macroeconomic time series facts: The effects of monetary policy, European Economic Review, 38, 975-1000.

Stock JH and Watson MW (2001).Forecasting output and inflation the role of asset prices. In NBER working paper 8180; 2001.

Uddin,G.A.;Alam,K.;Gow, J (2016). Population age structure and savings rate impacts on economic growth: Evidence from Australia. Economic Analysis and Policy,52,23-33.

UNPD (United Nations Population Division). (2015a). World population prospects: The 2015 revision. New York: Department of Economic and Social Affairs.

UNPD (United Nations Population Division). (2015b). World population ageing (ST/ESA/SER.A/390). Walker, A., \& Maltby, T. (2012). Active ageing: A strategic policy solution to demographic ageing in the European Union. International Journal of Social Welfare, 21(s1), S117S130.

Wang, K.M (2011) Health care expenditure and economic growth: Quantile panel -type analysis. Economic Modelling, 28(4),1536-1549.

Werblow, A.; Felder, S.; Zweifel, P.(2007) Population ageing and health care expenditure: a school of 'red herrings'?.Health Economics, 16(10),1109-1126.

Xu, J., \& Mills, A. (2019). 10 years of China's comprehensive health reform: a systems perspective. Health policy and planning.

Yip, W., Fu, H., Chen, A. T., Zhai, T., Jian, W., Xu, R., ... \& Mao, W. (2019). 10 years of healthcare reform in China: progress and gaps in universal health coverage. The Lancet, 394(10204), 1192-1204.

$\mathrm{Yu}, \mathrm{H}$. (2015). Universal health insurance coverage for 1.3 billion people: what accounts for China's success?. Health policy, 119(9), 1145-1152. 


\section{Appendix}

Figure A1: Comparisons between China and the USA for the key variables
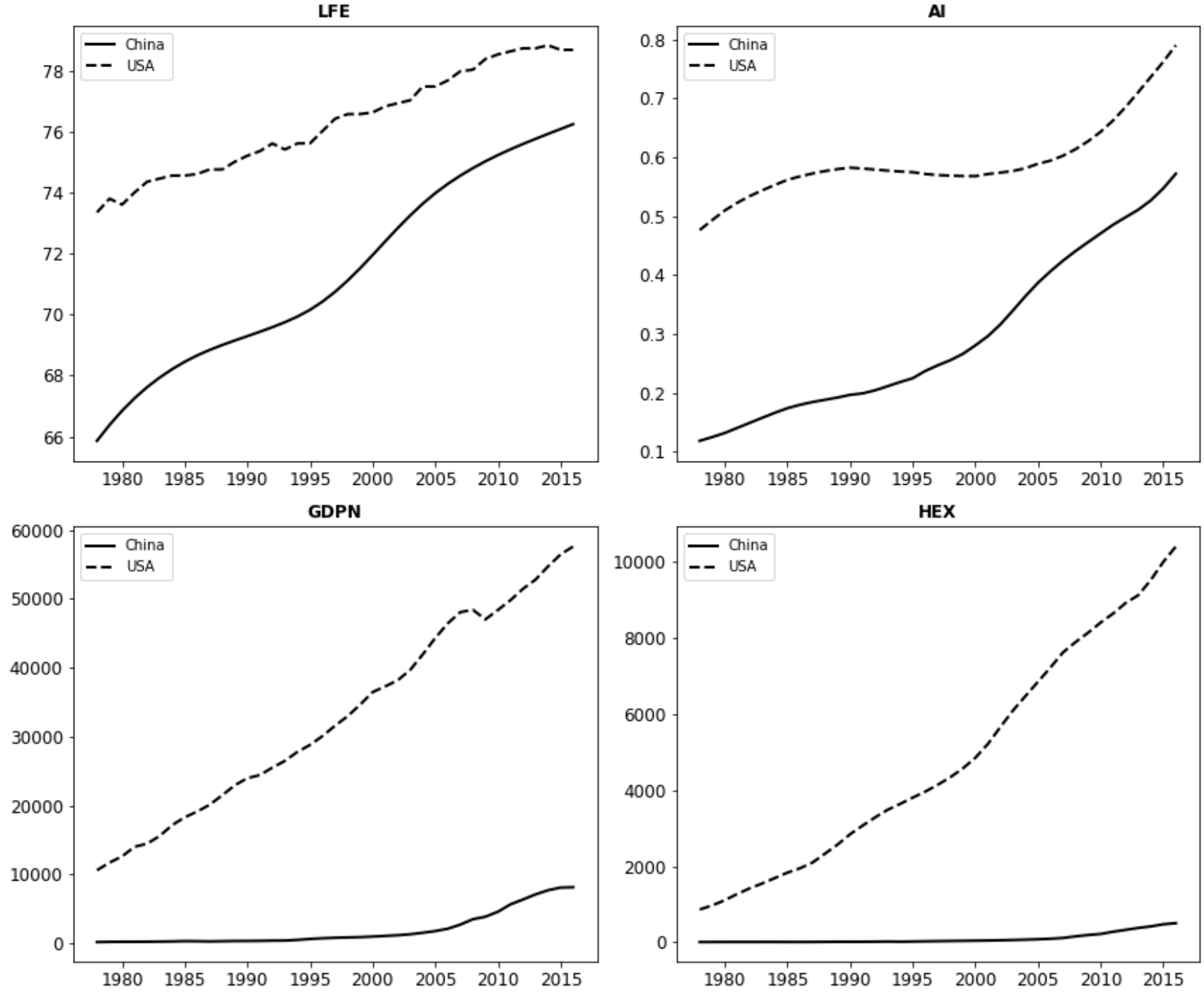
Figure A2: B-VAR impulse response functions with 95\% credible intervals of nominal gross domestic product per capita (GDPN), health expenditure per capita (HEX), life expectancy (LFE), ageing index (AI) for China (20-year horizon; nominal variables)
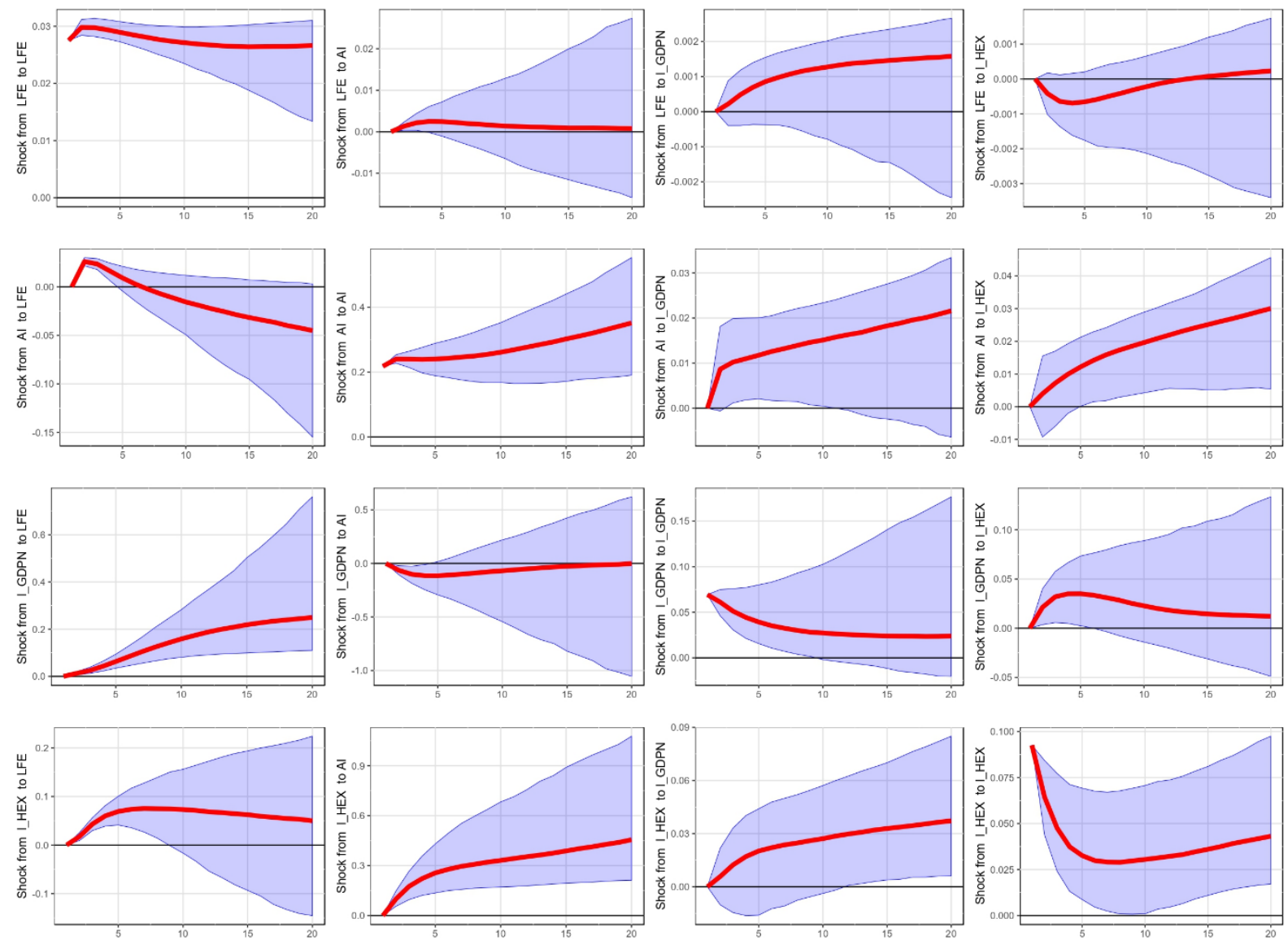
Figure A3: B-VAR impulse response functions with 95\% credible intervals of nominal gross domestic product per capita (GDPN), health expenditure per capita (HEX), life expectancy (LFE), ageing index (AI) for the USA (20-year horizon; nominal variables)
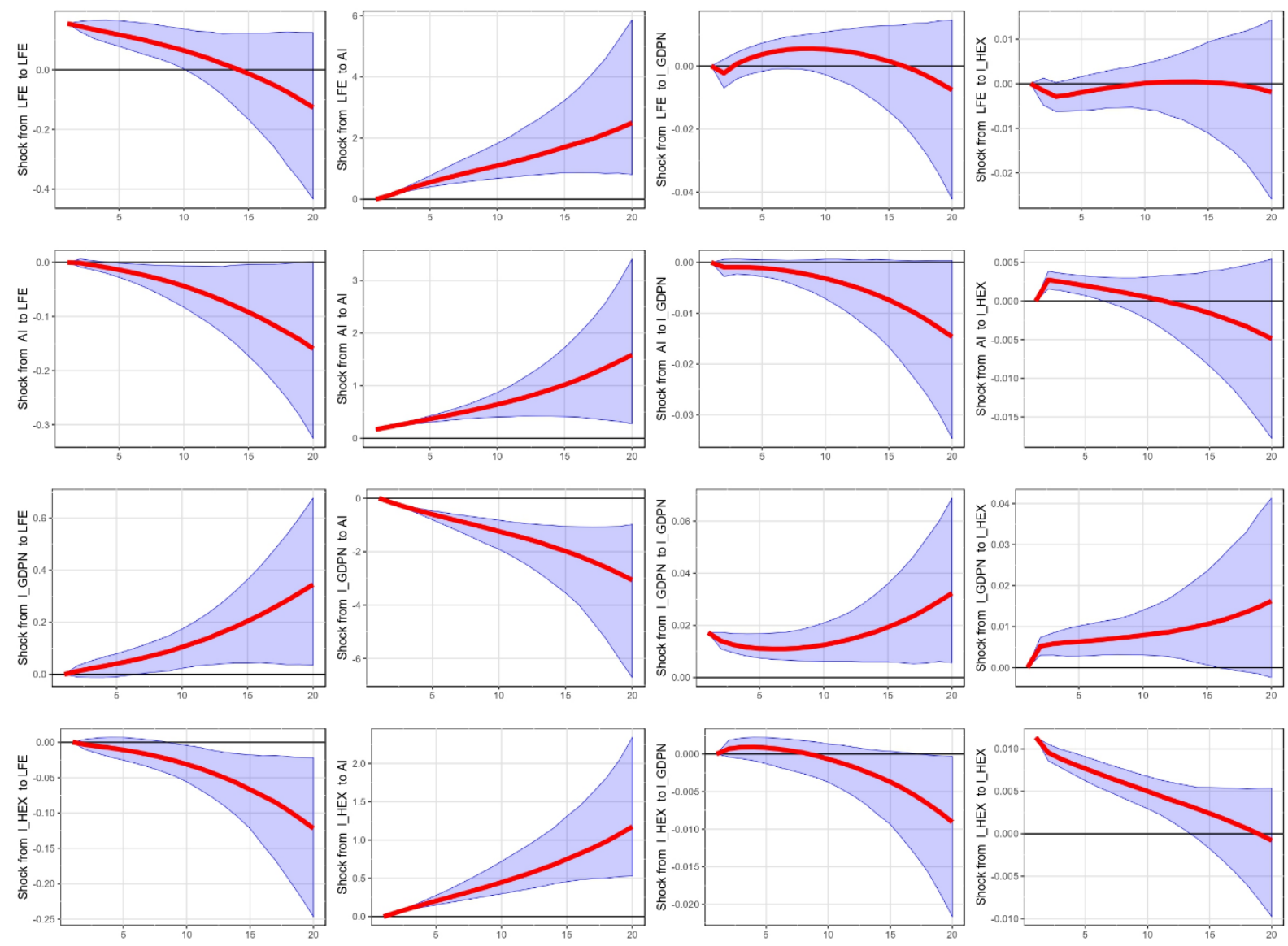
Table A1: A comparison between USA model and China model: Forecasting VAR vs B-VAR (real variables)

\begin{tabular}{|c|c|c|c|}
\hline & Variable & RMSE & MAE \\
\hline \multicolumn{4}{|l|}{ USA model } \\
\hline \multirow{4}{*}{ Standard VAR } & LFE & 0.24 & 0.23 \\
\hline & AI & 0.105 & 0.9 \\
\hline & GDPR & 0.29 & 0.28 \\
\hline & HEXR & 0.129 & 0.128 \\
\hline \multirow{4}{*}{ Minnesota prior } & LFE & 0.0 .39 & 0.026 \\
\hline & $\mathrm{AI}$ & 0.035 & 0.055 \\
\hline & GDPR & 0.056 & 0.024 \\
\hline & HEXR & 0.075 & 0.065 \\
\hline \multirow{5}{*}{$\begin{array}{l}\text { Normal-Wishart } \\
\text { prior }\end{array}$} & LFE & 0.256 & 0.24 \\
\hline & $\mathrm{AI}$ & 0.053 & 0.059 \\
\hline & GDPR & 0.074 & 0.079 \\
\hline & HEXR & 0.121 & 0.127 \\
\hline & Variable & RMSE & MAE \\
\hline \multicolumn{4}{|l|}{ China model } \\
\hline \multirow{4}{*}{ Standard VAR } & LFE & 0.63 & 0.61 \\
\hline & AI & 0.93 & 0.89 \\
\hline & GDPR & 0.67 & 0.59 \\
\hline & HEXR & 0.53 & 0.57 \\
\hline \multirow{4}{*}{ Minnesota prior } & LFE & 0.03 & 0.03 \\
\hline & AI & 0.06 & 0.04 \\
\hline & GDPR & 0.04 & 0.01 \\
\hline & HEXR & 0.03 & 0.01 \\
\hline \multirow{4}{*}{$\begin{array}{l}\text { Normal-Wishart } \\
\text { prior }\end{array}$} & LFE & 0.20 & 0.17 \\
\hline & AI & 0.58 & 0.58 \\
\hline & GDPR & 0.27 & 0.39 \\
\hline & HEXR & 0.63 & 0.61 \\
\hline
\end{tabular}

